\title{
An Exposition of Some Adapted Lexemes in Dholuo
}

\author{
Benard Odoyo Okal ${ }^{*}$, Florence Indede, Ernest Sangai Mohochi \\ School of Arts and Social Sciences, Department of Kiswahili and other African Languages, Maseno University-Kenya \\ *Corresponding Author: benardodoyo@yahoo.com
}

Copyright (C 2013 Horizon Research Publishing All rights reserved.

\begin{abstract}
The paper gives an exposition of some adapted English lexemes into Dholuo. The work relied on a descriptive design. Total purposive sampling technique was incorporated in collecting secondary data to saturation level. All the adapted nominal lexemes from the English Dholuo Dictionary $(E D D)$ were collected, qualitatively analyzed, edited and presented thematically by showing the adapted lexemes in various areas. The results indicate that adapted lexemes in this lexicographical work are manifested in the following areas: religion, people, subjects, places, measurements, clothing, vegetables, foodstuff, equipment, vehicles and months. We have gathered that as we adapt some lexemes from English into Dholuo, then phonemes such as $/ \int(\mathrm{sh}), \mathrm{z} /$ automatically change to $/ \mathrm{s} /, / \mathrm{v} /$ changes to $/ \mathrm{f} /$ and $/ \mathrm{q} /$ changes to $/ \mathrm{k} /$. We have concluded that English consonant phonemes such as $/ \int(\mathrm{sh}), \mathrm{z}, \mathrm{v}, \mathrm{q} /$ are not manifested in Dholuo. Therefore, translators have to adapt them by using both the transference and naturalization translation procedures in order to achieve the desirable translated text.
\end{abstract}

Keywords Translation, Dholuo, Lexemes, Adaptation

\section{Introduction}

To achieve the main theme of this work, our introduction begins with the concept of translation in which we have focused on the definition of translation, its brief history, the concept of equivalent, common problems of translation and some set principles to be considered by translators before embarking on the translation processes. The section also gives a brief background to Dholuo language that is the focal point of our discussion, population of its speakers and where it is spoken, its tonal features and syllable structures.

The word translation comes from a Latin lexeme 'translatio' that means restatement of forms of one language into another with the chief means of exchanging information between different languages [1,2]. This exchange or transfer of information is normally done by considering the the characteristic features of the source language (SL) and the target language (TL) in order to get the required equivalents $[3,4]$. The transfer of message can be on either written or oral texts. However, translation of these discourses whether in written form or oral in nature tend to vary in their statuses in that a written text has a higher status than an oral text therefore fidelity notion also varies in translation of written texts and interpretation that is normally manifested in oral utterances [5]. Translation has two major functions [6]: firstly, breaking a foreign language barrier to ease communication. Secondly, it helps in giving semantic equivalence between SL and TL by using various translation techniques and procedures. Translation is therefore instrumental to both bilinguals and the studies in bilingual lexicography.

The history of translation could be traced back to $3000 \mathrm{BC}$ especially at the advent of discoveries whereby knowledge, skills and products were to be disseminated from the place of origin to the other areas of the world for consumption [7]. The main concern of translation was to transfer information from the civilized states like Egypt to the other areas of the world [8]. By $16^{\text {th }}$ and $17^{\text {th }}$ Centuries, the discipline had already flourished in Europe as it was used in disseminating knowledge using Latin and Greek languages [9]. In addition, by $20^{\text {th }}$ and $21^{\text {st }}$ Centuries, translation was fully in practice due to increased need for faster communication [8].

As we transfer information from SL to TL, the main focus is generally the aspect of equivalents that are used to convey the desired meanings in the target text. [10] refers to these equivalents as synonyms. According to [10], there are two main synonyms namely: absolute synonym and near synonyms. Absolute synonym perfectly identifies contextually and semantically with each other in both SL and TL. This case is usually shown by the use of the formula such as $[\mathrm{A}=\mathrm{B}]$. For instance, if $[\mathrm{A}]$ is a goat then it is absolutely synonymous with $[\mathrm{B}]$ that is diel in Dholuo. Near synonyms are not always semantically and contextually identical in both languages thus translators are forced to look for any word that is somehow near in meaning with the source word.

Though [10] talks of two types of equivalents by using the term synonyms, on the other hand [11] uses the term equivalents and enumerates the following three types namely: symmetrical, semi-symmetrical and asymmetrical equivalents. The symmetrical equivalent is that which is similar in use both contextually and semantically in the SL and the TL $[12,13]$. Semi-symmetrical equivalent shows commonness in meaning however a divergence in meaning 
in the TL is also witnessed due to different cultural values $[14,15]$. Asymmetrical equivalent does not always show one to one corresponding relation of the SL word and the TL word. This kind of equivalent is normally witnessed in among others the fields of religion, food and traditions [16]. Asymmetrical equivalent can be shown by using a formula such as $[\mathrm{A} \neq \mathrm{B}]$ whereby lexeme $[\mathrm{A}]$ does not have similar equivalent $[\mathrm{B}]$. In such circumstances, translators are required to use adaptation technique to avoid probable loss of information.

Though translation is considered to be a very significant factor in bilingual communication processes, seemingly exact equivalence is somehow impossible because in some instances no translation could provide translation that is of perfect parallel to the source text [6]. Thus, there is always loss of information. What we normally do as translators is to give a near translation to fit into our cultural placements. Other notable common problems facing translators include: use of rhythm, sound differences, symbolism, puns (words with same sounds but different meanings) and also cultural allusions inhibited in the texts under discussion [6].

These translation problems are witnessed because of the existence of different cultural and traditional backgrounds, environmental variations of the languages, technological advancements, economic, political changes and even social set-ups of the people speaking these different languages. Thus in general, problems of translation occur because of existing cultural overlap, different lexical, grammatical and sound systems of the languages involved, and speakers also tend to segment many physical objects and all intellectual concepts differently [17].

Translation both as a theory and a process has also become so elusive to the translators. This is because formulating an adequate theory of translation actually takes place in our brains hence we do not know precisely what actually happens [18]. All these factors normally give translators very hard time in their works. In an attempt to solve the translation problems, many translators therefore employ various techniques to effectuate translation work. There are numerous translation techniques witnessed in the English Dholuo Dictionary (EDD) [19]. However, this study has singled out adaptation technique for analysis in order to pinpoint the various fields where the technique has been applied.

Since translation has numerous notable problems, it is always advisable that translators take into consideration many set principles before the application of translation techniques and procedures. [18] enumerates some of these set principles that: any translator should understand that language represents an aspect of culture, meaning of verbal symbols is normally defined indirectly by contrastive symbols and any given context tends to contain more information than the intended one. It should also be noted that in some instances there is no complete synonym in either one language or even two languages concerned. All languages and their cultures are ever changing both in the processes and structural levels, and sometimes speakers of most languages don't even realize that changes have occurred in the sounds and discourses thus stylistic models should always be put in place. In addition, translators should understand various models of discourses to be translated for instance narratives, descriptive, argumentative and conversational discourses.

Before discussing the application of adaptation technique in the $E D D$, we have found it necessary to give a brief history of Dholuo language. The brief history of Dholuo language gives information about where the language is spoken, relationship with other Nilotic language family, its tonal evaluation, affixation and syllabification. The coverage on these aspects sets a stage for the background information of the language in our presentation and its common structural composition and phonological features that assisted in the application of an adaptation translation technique in the $E D D$.

Dholuo is a Nilo-Saharan language that is widely used amongst Luo native speakers staying in Nyanza Province in Kenya, around Lake Victoria and along River Nile though some also stay in Uganda and Tanzania [20, 19, 21]. Luos relate linguistically with other groups in Uganda, Sudan, Ethiopia, Democratic Republic of Congo and Chad [22]. The other Nilo-Saharan languages are spoken in countries such as Sudan, Ethiopia, Uganda, Kenya and also Tanzania [23]. Approximately 12 million people speak Dholuo related languages in Sudan, Uganda, Democratic Republic of Congo, Ethiopia and other East African countries [24].

In general, the Nilo-Saharan language group includes other languages such as Turkana, Samburu, Kipsigis and Nandi of Kenya; Dholuo and Maasai spoken in Kenya and Tanzania; Padhola and Acholi spoken in Uganda and also Dinka, Pari and Nuer spoken in Sudan [23]. The Luos in Kenya neighbour Luhyia community on the Northern side of Lake Victoria, Nandis and Kipsigis on the Eastern side, and Kurias and Abagusii on the Southern side.

According to the report on census carried out in 2009 and officially released in 2010, Dholuo is spoken as first language by about 4.044 million people in Kenya [25]. The language is widely spoken by the Luo native speakers in the following counties in Kenya: Siaya, Kisumu, Homa Bay and Migori. Though Luos are divided into many clans such as Joka Jok, Joka Owiny, Joka Omollo and Joka Suba that are geographically spread in many regions of Nyanza Province [21], these major clans communicate well with each other despite the existence of a slight manifestation of dialectical aspects in speed in speech and vocabulary [19].

Dholuo is a tonal language manifested in both lexical and grammatical conditions $[20,19,26]$. This means that in some instances one lexeme can be pronounced differently to give different meanings. There are four distinct tones in Dholuo namely: high tone as in món (women), low tone as in lum (grass), falling tone as in nyany $\hat{a}$ (tomato) and rising tone as in lǎw (dress) [27].

Dholuo lexemes rely on affixation in their structures [19]. There are prefixes such as $\{$ nya- $\}$ as in [nyaguok] (puppy), $\{j a-/ j o-\}$ as in [jawuoth/jowuoth] (a traveler/travellers), $\{\mathrm{ra}-\}$ 
as in [rang'ol] (lame) and also $\{m a\}$ as in [makwar] (that is red). There are also suffixes such as $\{-r u o k\}$ as used in [winjruok] (agreement), $\{-n i\}$ as in [okombeni] (this cup), $\{-g i\}$ as in [okombegi] (these cups) and $\{-n o\}$ as in [okombeno] (that cup).

Dholuo syllables manifest the following four distinctive structures $[20,28,29]$ :

a. Consonant Vowel syllable $(\mathrm{CV})(\mathrm{CV})$ :

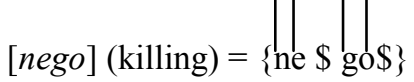

b. Vowel syllable $[u d o]($ Ostrich $)=\{\mathrm{u} \$ \mathrm{do} \$\}$

c. Consonant syllable (C): $[$ bul $]($ drum $)=\{\mathrm{bu} \$ 1 \$\}$

d. Consonant -Consonant Vowel syllable (CCV)

$$
[\text { ogwal }](\text { frog })=\{\text { o } \$ \text { gwa } \$ 1 \$\}
$$

\section{Objectives}

The work was guided by the following objectives:

i. To categorize adapted lexemes in the English Dholuo Dictionary.

ii. To explain translation processes applied in translating some English lexemes into Dholuo.

\section{Theory of the Study}

The research work was guided by the general Translation theory. The main objective of Translation theory is to give various strategies that can be used to translate a variety of texts $[17,18]$. Thus the theory provides a style with rules, pillars, variables of translation, analysis and a background on how to solve translation problems. The theory is an incitement of the relationship between the thought, meaning and language in translation $[17,18]$.

Four things are considered in the general translation theory [4]: firstly, the intention of the text. Secondly, purpose or intention of the translator where the translator should tell whether he would want to show original text as it is when translating to the TL so as to affect the reader or add his feelings and words which don't agree with the original text. Thirdly, consideration of the reader and the layout or setting of the text concerned. Fourthly, the quality of writing and the authority of the original text are also considered.

There are various approaches of translation theory which are caused by the following factors [30]: stylistic forms, author's intent, language diversity, different cultures of the languages involved, interpersonal communication, changes as witnessed in literary fashion, distinct contents and also circumstances involved. Other factors that bedevil translation theory are syntactic variations of languages, variations in the morphology of words and the assumed total numbers of the lexicon of the languages under study [31].

Translation theory involves perspectives or sub theories [30] namely: philological, linguistic, communicative and sociosemiotic. Philological perspective is concerned with the translation that is seemingly faithful in context, language form and the style like in the Bible and constitutional translations whereby fidelity to the original text is always embraced. Linguistic perspective involves translation by studying issues of the distinctive linguistic features of both SL and the TL. Communicative perspective relies generally on the aspects of communication theory such as sender, message, receiver, noise, feedback, medium and the milieu. This perspective embraces the issues of encoding and decoding messages for better understanding. The sociosemiotic perspective involves both the translation of words and the interpretation of paralinguistic features.

Though [30] talked of four perspectives, these four can be merged into two broad approaches which are referred to as the communicative and semantic [4]. The communicative approach is concerned with the use of a language in such a way that communicative meaning in a context is realized. However, communicative approach is not only used in the bilingual communication process alone but also in the monolingual communication. The communicative approach gives an idea that any translator is an active communicator and interpreter who takes into consideration both the normal monolingual and bilingual communication processes. According to [32], the figure 1 below gives a summary of a monolingual communication process:

Language A

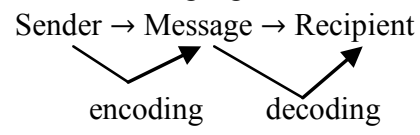

Figure 1. Monolingual Communication Process

Figure 1 indicates that normal monolingual communicative process that involves one single language tends to consist of the sender who encodes the message then the same message is decoded by the recipient. On the other hand, a bilingual communication process that is the main focal point of a translator consists of the following steps as adapted from [32] in the figure 2 below:

SL

TL

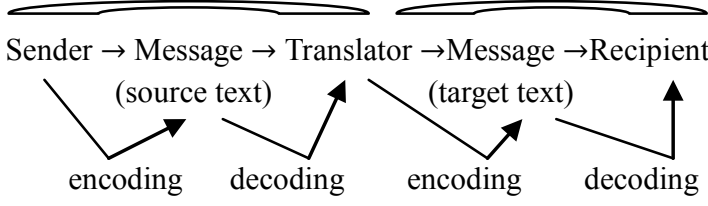

Figure 2. Bilingual Communication Process

Figure 2 indicates that a translator has a double task of involving both codes of encoding and decoding messages. 
The translator decodes message from the sender in the SL, encodes it in the TL then decoded again by the recipient especially of the TL in the target text. In general, bilingual communication process involves the sender with intended objectives passed through a well formed utterances, the message is decoded by the translator who later passes it on to the recipient for consumption [33].

Semantic translation is basically concerned with language rules so as to give the true meaning in a given context. The study has relied on the semantic approach in order to compare both English and Dholuo lexemes when adaptation technique is used. Though, this work has majorly relied on adaptation technique, the general translation theory involves a variety of other techniques namely: word for word, literal, free, pragmatic, aesthetic, ethnographic, faithful, semantic, idiomatic and information translation among others $[6,4]$.

Word for word translation involves giving a one to one provision of an equivalent of the SL in the TL by referring to each and every word. Literal translation includes word for word translation but at the same time considering structural composition of the sentences in both languages. Free translation occurs when a translator tends to avoid the linguistic structural composition of the SL and instead use other structures in the TL. Pragmatic translation involves giving meaning of the SL in the TL by considering context to simplify the intended meaning. Aesthetic translation is generally involved in the literary works whereby structure and form of the text in the SL is followed so as to uphold the stylistic appearance of the text in the TL.

Where traditional background of the people is considered to give the desirable equivalent, an ethnographic translation is generally involved. Faithful translation is used in serious and critical texts such as the Bible and constitution whereby truthfulness, structure and style are generally adhered to without deviations. Idiomatic translation is concerned with the inclusion of idioms as equivalents in the TL which were not witnessed at all in the SL. Sometimes translators use information translation in order to pass on the intended information in summary. This is where a whole text of many pages is just translated into may be a single paragraph to pass information. Adaptation is a translation technique whereby the TL adapts lexemes from the SL by adhering to its phonological and morphological rules [34]. The adaptation normally happens because not all languages are lexically sufficient to refer to the many items within any given environment. Therefore adaptation occurs during language contacts.

Besides the many translation techniques in the translation theory, there are also various procedures applied in order to get the desirable equivalents. Procedures are methods used to formulate an equivalent in the TL [4]. There are numerous translation procedures such as through procedure, transposition, recasting, modulation, compensation, transference and naturalization among others [4, 32]. Through translation procedure is used in getting equivalents of names of places, people and even organizations. Thus the procedure is more appropriate in Onomastics where names are studied. We may also change the grammar from SL to TL whereby a singular lexeme in the SL is grammatically changed to plural form in the TL when the transposition procedure is applied. In the recasting procedure, translators tend to modify the order of equivalents in the TL. Sometimes we may change view points as we use the modulation procedure. In cases where cultural sounds and metaphors are involved, translators are advised to use compensation translation procedure.

Though translation has many techniques and procedures, this study has only singled out the application of adaptation technique in the translation of English nominal lexemes into Dholuo by showing how it has been used effectively in the $E D D$ by [19]. In our endeavor to accomplish the study, we have given a brief comparative analysis of some English and Dholuo phonemes by showing how they are transferred during the application of the adaptation technique.

Adaptation technique involves two main procedures namely: transference and naturalization. Transference procedures requires a translator to understand the phonologies of both the SL and TL by comparing their phonemes both vowels and consonants just as we have indicated between English and Dholuo. Thus a translator is supposed to be well versed with the phonological rules of both the SL and the TL. For instance, the lexeme Bishop in English has a $/ \mathrm{sh} /$ phoneme that is normally transferred as $/ \mathrm{s} /$ phoneme in Dholuo.

After transference, the study on the morphology of both languages also becomes handy to assist in the application of naturalization translation procedure. The knowledge gained on morphology basically helps translators to write the transferred words using the correct structural format of words of the TL. For example the word Bishop in English is naturalized as Bisop by following the morphological rules of Dholuo. In a nutshell, transference procedure requires knowledge of phonology while naturalization procedure requires knowledge of morphology of both the SL and TL.

\section{Methods}

The study used a descriptive design. The work involved reading, observation, analysis of adaptation technique and showing how it has been applied in the $E D D$. The work relied on the analysis of secondary data from $E D D$ focusing on the English and Dholuo nominal category. This was necessitated by the fact that nominal lexemes are readily subjected to adaptation technique when translated from one language to the other. Total purposive sampling procedure was used in collecting all the English nominal lexemes translated into Dholuo by using the adaptation technique until the saturation levels were attained.

The study involved the use of document analysis of the secondary data of English nominal lexemes. The results were edited, coded and classified for easy understanding hence their equivalents provided in Dholuo. The data is presented both in continuous prose and lexicographically to ease 
reading and clearly show the structural forms of bilingual lexicography where headwords of the SL are generally arranged alphabetically on the left side of the text and the equivalents in the TL given on the right hand side. For this article, English lexemes are arranged alphabetically on the left hand side and equivalents in Dholuo on the right hand side.

\section{Results}

In many instances, adaptation is witnessed in the fields of technology, economics, education and politics [35] and also science among others. Adaptation is normally used in the scientific field to uphold the traditions, sense and originality [36]. However, there are instances whereby we can adapt by borrowing lexemes from the SL to the TL without any alterations on the structure or form. English adapted by borrowing lexemes from French such as sovereign, crown, state, government, burglar, accuse, plea, fee, attorney general, enemy, danger, soldier, guard, religion, service, virgin and trinity [36].

Adaptation is not only between English and Dholuo alone but also witnessed amongst other African languages. For instance, Kiswahili language which is both a national and one of the official languages in Kenya, a lingua franca of East Africa and one of the widely spoken international languages of the world has adapted many lexemes from other languages outside Africa to enrich its lexicon. For example, baftah (bafta) and karan (karani) from Persian, lenco (leso) and mesa (meza) from Portuguese, balyus (balozi) and efendy (afande) from Turkish, champ (shamba) and duvin (divai) from French, and notice (notisi), office (ofisi) and police (polisi) from English [37]. The Sepedi language adapted lexemes such as professor (moprofesa), March (matshe), December (Desemere), gramophone (keramafomo) and pen (pene) from English [38].

Dholuo has adapted many lexemes from English as witnessed in the following section below. From the $E D D$ [19], the adapted lexemes from English language into Dholuo are manifested in various categories such as religion, people, subjects, places, measurements, clothing, vegetables, foodstuff, equipment, vehicles and months. We have ordered alphabetically on the left side of this text the adapted English lexemes while Dholuo lexemes are italicized and indicated on the right hand side for ease of identification. This organization of data embraces the lexicographical principles of bilingual text presentations.

Generally Luos and even other Africans traditionally upheld the principles of traditional worship. They had various shrines for worship and their traditional spiritual leaders to guide the faithful. Religion was by far used for cleansing the abominable deeds of the communities, people and for requests for blessings. In this regard, the modern ways of worship were not adhered to. However, as Dholuo got into contact with English that had already incorporated the modern ways of worship with many terminologies to refer to adherents, principles of worship and even different types of religion, adaptation technique had to be used to enrich Dholuo religious lexicon. Thus, in the religious field, the following lexemes were witnessed:

\section{baptism batiso \\ catechism katakisim \\ catholic katholik \\ Christian Jakristo}

We have realized from the above examples that when borrowing by adaptation is done, the prefixes $\{\mathrm{ja}-/ \mathrm{jo}-\}$ are used to depict a person as can be seen in ja-kristo (Christian) and ja-katholik (catholic). The prefixes $\{\mathrm{ja}-/ \mathrm{jo}-\}$ are also witnessed when referring to people not necessarily in the field of religion for instance: Arab (ja-rabu), scout (ja-skaut) and Romans (Jo-roma). The prefix \{jo-\} denotes plurality form embedded on some derived Dholuo nouns as can be seen in Romans (Jo-roma) and the prefix $\{j a-\}$ denotes singularity. Other names of people are just adapted without adding the prefix $\{\mathrm{ja}-/ \mathrm{jo}-\}$ as can be seen in the following lexemes:

askari askari
Bishop $\quad$ Bisop
Indian
police
polisi

Traditionally Luos depended more on art and craft to make many items for their daily use. These crafts were not necessarily regarded as subjects since they were primarily acquired trough apprenticeship without formal classroom orientation. They could show direction of places by pointing, tell their stories and histories especially orally and even brew their beers not knowing that a distinct science was involved. However, as interaction with the English language continued, distinct subjects appeared. A few subject areas were therefor derived or adapted in this work:

\section{Geography Jografi \\ History Historia \\ Science Sayans}

There are no prefixes to these lexemes however the phonological and morphological rules of Dholuo are adhered to.

Basically, Luos used steps sizes of the legs and also the sizes of one's arm or even ropes in order to show lengths. These methods looked cumbersome but were somehow effective in their traditional settings. However, as modernity was embraced, Dholuo speakers ended up adapting many terminologies to assist in measuring distances and the degrees. We have referred to these terminologies as lexemes in the field of measurements. In the $E D D$, the field of measurements showed the adaptation of the following lexemes:

degree digri 


$$
\begin{array}{ll}
\text { grade } & \text { gredi } \\
\text { inch } & \text { inji } \\
\text { yard } & \text { yad } \\
\text { metre } & \text { mita } \\
\text { mile } & \text { mailo }
\end{array}
$$

Traditionally, Luos relied much more on soft cowhide to be used both as beddings and clothe. In other instances, owalo (sisal skirt) was also used by women to cover their bodies. However, as they continued embracing modernity with western materials and fashion flooding their market places, a number of items were introduced that were adapted in Dholuo. For example:

badge baj
bandage bandej
coat koti
jacket jaket
khaki kaki
lace les
skirt skat
socks soksi
underwear andaway
zip sip
towel taulo

Luos had a tendency of traditionally having their meals in their homesteads or even the work places and also work in their traditional special rest huts referred to as abila in Dholuo especially for old men. However, due to contact with English, a number of words were adapted to refer to eating places, confinement, working offices and even the pathways for the train. We have grouped all these as names referring to places. Thus, when referring to the category of places, the following adapted words were witnessed:

$$
\begin{array}{ll}
\text { hotel } & \text { otel } \\
\text { jail } & \text { jela } \\
\text { office } & \text { ofis } \\
\text { rail } & \text { reru }
\end{array}
$$

On the other hand, the field of vegetables included a variety of traditionally acquired vegetables for instance kandhira (African kales), obwolo (mushroom) and even osuga (African nightshade) among others. These examples had a one to one equivalent however the exotic ones were adapted. Though we are aware of many more adapted names of vegetables from English into Dholuo, in the EDD, the field of vegetables shows only one single adapted lexeme:

$$
\text { cabbage kabich }
$$

Dholuo adapted a variety of foods that were primarily not common in the menu of the native Dholuo speakers. We have gathered that the foods that were derived or adapted into Dholuo from the $E D D$ include:

biscuit biskut

$$
\begin{array}{ll}
\text { cake } & \text { kek } \\
\text { cocoa } & \text { koko } \\
\text { scone } & \text { skonj } \\
\text { sugar } & \text { sukari }
\end{array}
$$

Luos had their on traditional equipment, modes of transport and even ways of referring to the names of months in order to accomplish various activities in their daily undertakings. However, due to influence of the other languages, many more items were embraced by the Luos which required the provision of equivalents. But because of two different cultures of both English and Dholuo, adaptation technique was inevitable. The equipment, vehicles and names of months adapted in this work were as hereunder stated:

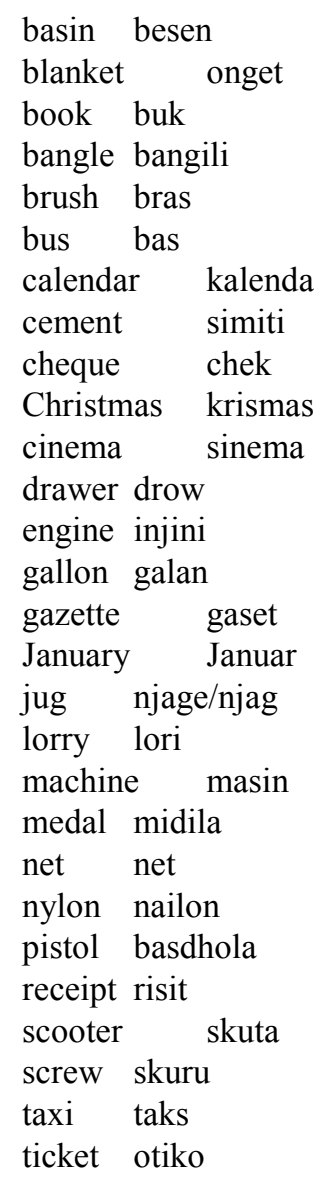

\section{Discussion}

From the list of lexemes witnessed in the $E D D$, we have realized that when lexemes are assimilated into a language by adaptation technique then the TL adapts by adhering to its phonological and morphological rules [34]. This is normally and effectively carried out by the application of transference and naturalization translation procedures [4].

Transference is loaning of words by transcription whereby a SL lexeme is transferred to fit the structural word orientation of a TL by transposing their phonemes. This is because of lack of lexicalized correspondence and stylistic or 
rhetorical reasons. The scenario is witnessed in the changes whereby English consonant phonemes like the /v, z, $\int(\mathrm{sh}) /$ tend to change to other phonemes during adaptation to fit into the existing Dholuo phonemes [39]. For instance, English phonemes such as $/ \int(\mathrm{sh}), \mathrm{z} /$ change to $/ \mathrm{s} /$ [39]. These changes enshrined in the works of $[40,39]$ are also manifested in the work of [19]. For example:

$\begin{array}{ll}\text { Bishop Bisop } \\ \text { brush bras } \\ \text { gazette } \\ \text { machine } & \text { masin }\end{array}$

On the other hand, naturalization refers to adapting a SL lexeme first to the normal pronunciation then to the normal morphology of the TL and then finally formalized in the TL vocabulary for the effective communication of the speech community. In regards to the above lexemes like bishop (bisop) and brush (bras), the phoneme $/ \int$ (sh)/ changes to /s/. Likewise, the phoneme $/ \mathrm{z} /$ in the lexeme gazette also changes to $/ \mathrm{s} /$ thus the word is adapted by being naturalized into Dholuo as (gaset). These changes have to conform to existing number of Dholuo phonemes. In general, there are 26 consonant phonemes of Dholuo [20, 41, 27]: [/b, t/č, d, ठ,

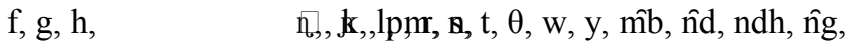
$\mathrm{nj} /$ / in which transference and naturalization procedures tend to adhere to when adaptation technique is applied from English into Dholuo.

Comparatively the following phonemes are not found in Dholuo: $/ \int, \mathrm{v}, \mathrm{z}, \gamma /$ but are found in English. Therefore, when one is tasked with the translation work from one language with the above mentioned phonemes into Dholuo and would want to apply adaptation technique then the proper understanding of Dholuo phonemes should be taken into account. As we use transference translation procedure especially from English into Dholuo, then the following examples of changes of phonemes will always tend to occur:

Table 1. Changes of Phonemes from English into Dholuo

\begin{tabular}{|c|c|c|c|}
\hline $\begin{array}{c}\text { English } \\
\text { Phonemes }\end{array}$ & $\begin{array}{c}\text { Changes to } \\
\text { Dholuo }\end{array}$ & $\begin{array}{c}\text { Examples of } \\
\text { English } \\
\text { Lexemes }\end{array}$ & $\begin{array}{c}\text { Adapted } \\
\text { lexemes in } \\
\text { Dholuo }\end{array}$ \\
\hline$/ \int(\mathrm{sh}) /$ & $/ \mathrm{s} /$ & Bishop & Bisop \\
\hline$/ \mathrm{z} /$ & $/ \mathrm{s} /$ & gazette & gaset \\
\hline$/ \mathrm{v} /$ & $/ \mathrm{f} /$ & television & telefison \\
\hline$/ \mathrm{q} /$ & $/ \mathrm{k} /$ & cheque & chek \\
\hline
\end{tabular}

\section{Conclusion}

We have realized that adaptation technique is very vital in any translation work. Though the technique is basically found in translation studies, it is also regarded as a sociolinguistic process which occurs when cultures have contact [4]. Thus, it is regarded as the "freest" form of translation [4]. However, when we intend to use it for translation purposes of various texts that involve different languages with varied structural, cultural and geographical backgrounds then we must understand the phonological and morphological rules of both the SL and TL. In addition, adaptation technique is normally applied in translation processes because of existing different cultural backgrounds of languages, scientific advancements, political, social and commercial factors involved in communication among others. In general, as speech communities interact then adaptation of lexemes will always tend to occur.

\section{REFERENCES}

[1] W. Bright. International Encyclopedia of Linguistics, Oxford University Press, London, 1991.

[2] T. McArthur (Ed.). Oxford Companion to the English Language, Oxford University Press, Oxford, 1992.

[3] J. C. Catford. A Linguistic Theory of Translation, Oxford University Press, Oxford, 1965.

[4] P. Newmark. Textbook of Translation, Prentice Hall International, New York, 1988.

[5] B. Harris. Prolegomenon to a Study of the Difference between Teaching Translation and Teaching Interpretation, University of Ottawa Press, Ottawa, 1981.

[6] D. Crystal. The Cambridge Encyclopedia of Language, Cambridge University Press, Cambridge, 1987.

[7] M. Mukuthuria. Mchango wa Tafsiri za Taaluma za Kiswahili. In K. Njogu (Ed.), Kiswahili na Elimu Nchini Kenya, Twaweza Communications \& CHAKITA, Nairobi, 119-134, 2007.

[8] N. L. Shitemi. Taswira za Tafsiri, Mielekeo ya Ufundishaji na Maendeleo katika Taaluma ya Kiswahili. In K. Njogu (Ed.), Kiswahili na Elimu Nchini Kenya, Twaweza Communications \& CHAKITA, Nairobi, 135-157, 2007.

[9] H. J. K. Mwansoko. Kitangulizi cha Tafsiri: Nadharia na Mbinu, TUKI, Dar es Salaam, 1996.

[10] L. Zgusta. Manual of Lexicography, Academia, Prague, 1971.

[11] E. H. Klapicova. Composition of the Entry in a Bilingual Dictionary, 2005. Online Available at: www.skase/Volumes/ JTL04/05.pdf

[12] D. I. Melamed. Word-to-Word Models of Translational Equivalence. Computational Linguistics, 26, 490-497, 2000. Online Available at: http://acl.ldc.upenn.edu/P/P97-1063.pd

[13] D. Tufis, A. Barbu. Computational Bilingual Lexicography: An Automatic Extraction of Translation Dictionaries. Journal of Information Science and Technology, Romanian Academy Center for Artificial Intelligence, Racai, 4 (3), 2001.

[14] T. Piotrowski. Problems in Bilingual Lexicography, Wydawnictwo Uniwersytetu Wrocławskiego, Wrocław, 1994. Online Available at: http://citiseerx.ist.psu.edu/viewdoc/...rep=rep1\&type=pdf 
[15] M. J. Mongwe. The Role of the South African National Lexicography Units in the Planning and Compilation of Multifunctional Bilingual Dictionaries, Master of Art Thesis, Stellenbosch University, Republic of South Africa, 2006. Online Available at: http://hdLhandle.net/10019.1/2177

[16] M. Podolej. Culture in Bilingual Dictionaries: Analysis of Cultural Content and Culture-Specific Vocabulary in E-P-E Dictionaries, 2009. Online Available at: http://ifa.amu.edu.pl/fa/files/Podolej.pdf

[17] P. Newmark. Approaches to Translation, Prentice Hall International, Great Britain, 1982.

[18] E. A. Nida. Theories of Translation, 2006. Online Available at: http://www.pliegosdeyuste.eu/n4pliegos/eugeneanida. pdf

[19] A. B. Odaga. English Dholuo Dictionary, Lake Publishers and Enterprises Ltd, Kisumu, 1997.

[20] A. N. Tucker. A Grammar of Kenya Luo (Dholuo), Rudiger Koppe Verlag, Koln, 1994.

[21] J. O. Kokwaro, T. Johns. Luo Biological Dictionary, East African Educational Publishers, Nairobi, 1998.

[22] O. O. McOnyango. Preface, English-Dholuo Dictionary, Lake Publishers and Enterprises Ltd, Kisumu, v-vi, 1997.

[23] V. Webb, Kembo-Sure (Eds.), African Voices. An Introduction to the Languages and Linguistics of Africa. Oxford University Press, Southern Africa, 2000.

[24] K. King'ei. Misingi ya Isimujamii, Taasisi ya Taaluma za Kiswahili, Chuo Kikuu cha Dar es Salaam, 2010.

[25] D. Nation. National Census, Nation Media Group, Nairobi, 1-8, September 1, 2010.

[26] J. Habwe, P. Karanja. Misingi ya Sarufi, Phoenix Publishers, Nairobi, 2004.

[27] S. Cable. Some Basic Facts about the Dholuo Language, 2009. Online Available at: people.umass.edu/scable/LING748-FA09/Materials/H andouts/Dholuo-Basics.pdf

[28] P. Bye. Eliminating Exchange Rules in Dholuo, 2006. Online Available at: http://hum.uit.no/a/bye/Papers/Dholuo-squib.pdf

[29] B. Smith. Voicing in the Dholuo Nominal Paradigm, 2009. Online Available at: http://people.umass.edu/bwsmith/papers/bwsmith-dhol uo-nominal-paradigm.pdf

[30] E. A. Nida. Theories of Translation. Traduction, Terminologie, Redaction, 19-32, 1991. Online Available at: http://www.erudit.org/revue/ttr/1991/v4/n1/037079ar.pdf

[31] R. J. Decker. Translation Theory, Baptist Bible Seminary, Pennsylvania Clarks Summit, 1998. Online Available at: http://faculty.bbc.edu/rdecker/documents/ESV_ReviewETS. pdf

[32] K. E. Jensen. Translation and Translation Theory, Lecture notes, University of Aalborg, Week 1(36), 2008. Online Available at: www.hum.aau.dk/ OT08/OTLNI.pdf

[33] A. Cruse. Meaning in Language: An Introduction to
Semantics and Pragmatics. $3^{\text {rd }}$ Ed, Oxford University Press, Oxford, 2011.

[34] J. Laver. Principles of Phonetics, Cambridge University Press, Cambridge, 1994.

[35] K. S. Mahlangu. The Lemmatisation of Loan Words in an isiNdebele Bilingual Scholars Dictionary. Abstract of the $11^{\text {th }}$ International Conference of the African Association for Lexicography, University of Venda for Science and Technology, Thohoyandou, Republic of South Africa, 3-7 July, 31-32, $2006 . \quad$ Online Available at: http://afrilex.africanlanguages.com/afrilex2006.pdf

[36] E. Hatch, C. Brown. Vocabulary, Semantics and Language Education, Cambridge University Press, Cambridge, 1995.

[37] S. Chiraghdin, M. E. Mnyampala. Historia ya Kiswahili, Oxford University Press, Dar es Salaam, 1977.

[38] D. Prinsloo, A. R. Chuwa, E. Taljard. The Lexicons of Africa. In V. Webb, Kembo - Sure (Ed.), African Voices: An Introduction to Language and Linguistics of Africa, Southern Africa: Oxford University Press, 220-244, 2000.

[39] E. Kembo-Sure. Language Attitude, Use and Proficiency. A Sociolinguistic Study of English in Kenya, Doctor of Philosophy Thesis, Moi University, Kenya, 1996.

[40] D. Okoth-Okombo. Dholuo Morphophonemic. A Generative Framework, The Language and Dialect Atlas of Kenya Supplement 2, Dietrich Reimer, Berlin, 1982.

[41] P. de Lacy. Morpho-phonological Polarity, 2009. Online Available at: www.paudelacynet/polarity/delacy-2009-Morphophological polarity. pdf 